\title{
ALKOHOL OG SELVMORD
}

Ved Ingeborg Rossow, Statens institutt for alkohol- og narkotikaforskning

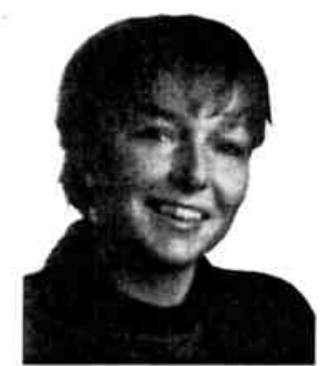

Ingeborg Rossow er epidemiolog og har de siste 4 år arbeidet ved Statens institutt for alkohol-og narkotikaforskning(SIFA). Et hovedprosjekt har vært empiriske studier av sammenhenger mellom rusmiddelbruk og suicidal atferd. Hun har publisert en rekke artikler innen dette området. Øurig forskningsvirksomhet er bl a knyttet til områdene helserelatert atferd, og rusmiddelbruk og dødelighet.

\section{"Whenever paths to the dark side of human life are to be explored, alcohol abuse is a track not to be omitted"}

Thor Norström, 1987

$\mathbf{N}$ orge har tradisjonelt ligget lavt i forhold til de fleste europeiske land både når det gjelder selvmordsrater og rusmiddelmisbruk. I etterkrigstiden har vi imidlertid sett en betydelig $\emptyset \mathrm{kning}$ av selvmordsraten. Blant menn er selvmordstallene mer enn fordoblet fra 1960 til 1990. Totalt var det 658 personer som døde ved selvmord i 1990, mens

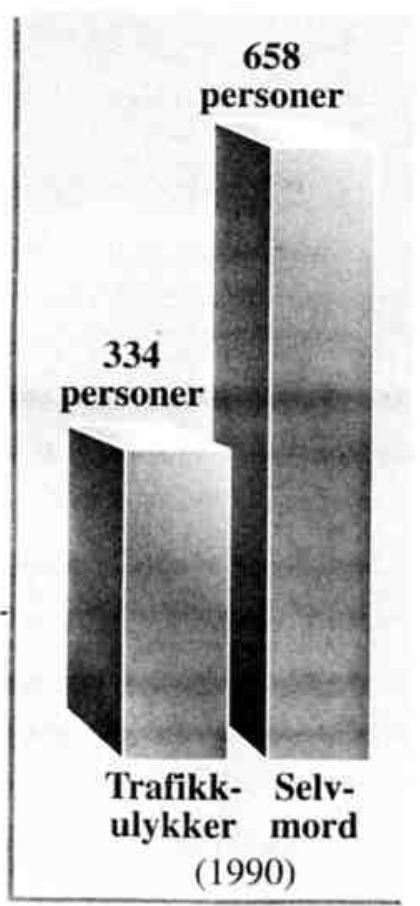
antallet drepte i trafikken til sammenlikning var 334 . Økningen i selvmordstallene i Norge har vœrt størst blant unge menn, og Norge er det landet i Europa nest etter Irland som har hatt den største prosentvise $\varnothing$ kningen i selvmord blant unge menn i denne perioden. Trafikkulykker og selvmord er nå de vanligste dødsårsakene blant unge menn. Siden 1950-tallet er alkoholkonsumet i Norge også omtrent fordoblet, fra 2,76 liter ren alkohol per innbygger over 15 år i 1951 til 4,99 liter i 1990, og vi antar at antallet alkoholmisbrukere er firedoblet i løpet av denne perioden.

Det at vi finner parallelle trender over tid for alkoholbruk og selvmord, er imidlertid ingen tilstrekkelig indikator for at det er noe annet enn en rent statistisk sammenheng uten substansiell mening, og langt mindre et årsaks/virkningsforhold mellom disse fenomenene. En rekke studier har imidlertid vist at alkoholbruk og alkoholmisbruk er blant de viktigere risikofaktorene for suicidal atferd. Vi skal i det følgende først se litt noermere på hva slags mekanismer som kan tenkes å generere ulike typer sammenhenger.

\section{Hvordan kan vi forklare sammenhengene?}

Når alkoholbruk eller alkoholmisbruk har betydning ved selvmord, kan det dreie seg om ulike typer mekanismer (kfr Roy \& Linnoila 1986; Skog 1991; Lester 1992; Retterstøl 1995). Selvmord kan være avslutningen på et langvarig alkoholmisbruk med gradvis sosial isolering og psykiske problemer som følge av misbruket. For noen vil personlighetsegenskaper og psykisk helse være predisponerende både for selvmord og for rusmiddelmisbruk, og begge deler vil kunne tjene som fluktvei eller problemløsningsstrategi.

Også blant moderate alkoholbrukere kan beruselse spille en rolle. Depresjon, selvmedlidenhet og selvmordstanker kan ofte bli mer framtredende under beruselse samtidig som barrierene for å skade seg selv blir mindre. Alkoholberuselsen kan derved bli en utløsende faktor ved selvmord.

I noen tilfelle brukes alkohol i tilknytning til den suicidale atferden $i$ den hensikt å redusere angst, eller "drikke seg til mot", og å dempe smertefølelse. I slike tilfelle kan beruselsen mer vœre å betrakte som en del av selvbeskadigelsen snarere enn som en årsak til handlingen.

\section{Sammenhenger pà individnivá}

Hovedtyngden av forskningslitteraturen om alkoholbruk og selvmord er knyttet til to typer empiriske tilnœrminger;

1) Forekomsten av selvmord og selvmordsfors $\phi k$ blant alkoholmisbrukere

2) Alkoholmisbruk blant pasienter med selvmordsfors $\phi \mathrm{k}$ eller blant dem som har tatt sitt eget liv

Oversiktsartikler over litteraturen på området har også i hovedsak fokusert tilsvarende på denne typen av empiriske studier. En rekke studier har vist at alkoholmisbrukere har en betydelig forhøyet risiko for selvmord. Disse studiene bygger gjerne på oppfølginger av utvalg av klienter som har vært til behandling for alkoholmisbruk. Den beregnede overdødeligheten ved selvmord fra disse studiene varierer betydelig.

I Dette er en omarbeidet versjon av et kapittel (også kalt "Alkohol og selvmord") i Pedersen W. og Waal H.: Rusmidler og veivalg. Osio: Cappelen, 1996. 
Enkelte studier viser en forøket risiko for selvmord blant alkoholmisbrukere på omkring 2 (altså at alkoholmisbrukere har en dobbelt så høy selvmordsrisiko som andre) (Vaillant 1983). Andre studier igjen har beregnet at alkoholmisbrukere har en selvmordsrisiko som er 25 ganger større enn den man finner i befolkningen for $ø$ vrig (Nicholls et al 1974). Den betydelige variasjonen i beregnet overdødelighet ved selvmord som vi finner mellom ulike studier, kan nok delvis forklares med metodeforskjeller. En annen forklaring kan vœre at mange av disse studiene bygger på utvalg av klienter fra en enkelt eller fra noen få behandlingsinstitusjoner, slik at variasjonen i selvmordsdødelighet også kan gjenspeile ulikheter i utvalgene av alkoholmisbrukere. I Norge er det gjort to større oppfølgingsstudier av overdødelighet ved selvmord blant alkoholmisbrukere. Sundby (1967) fant at blant menn som var innlagt i psykiatriske sykehus for alkoholmisbruk, var det 8 ganger så mange selv-

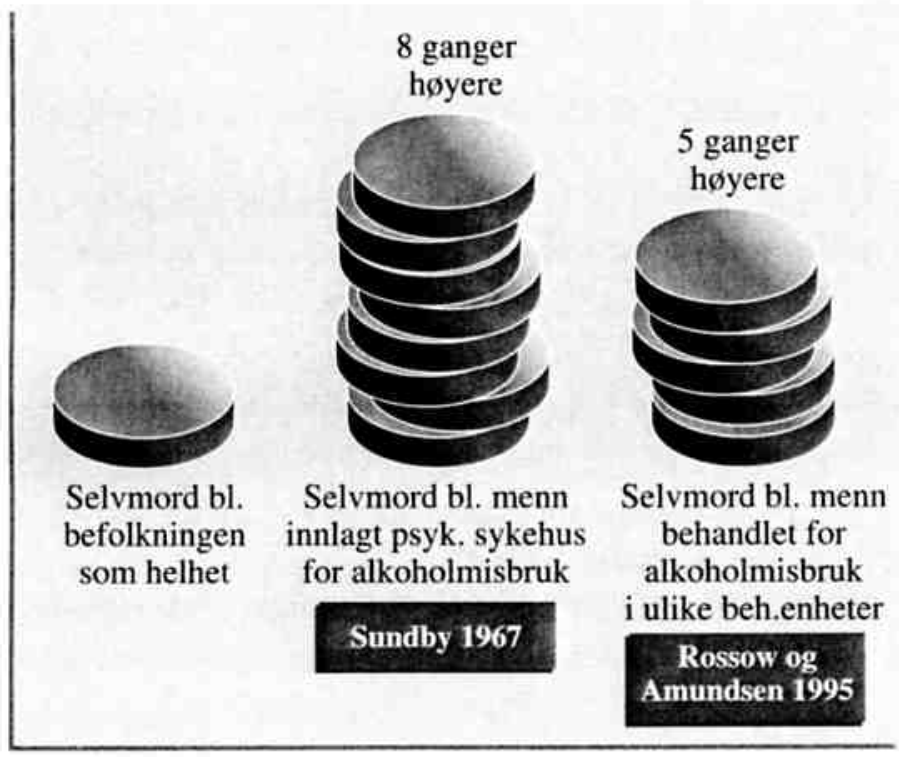

mord som blant menn i befolkningen som helhet. Rossow og Amundsen (1995) fant at antall selvmord blant menn som var behandlet for alkoholmisbruk i ulike behandlingsenheter (med unntak av psykiatriske sykehus) var 5 ganger så høyt som blant andre menn.

Selv om disse to norske studiene gir anslag for overdødelighet ved selvmord som ligger mer "midt på treet" og relativt nœert hverandre sammenliknet med den samlede forskningslitteraturen, er det likevel en forskjell her som kan ha substansielle fortolkninger.

Alkoholmisbrukerne i Sundbys materiale var behandlet i psykiatriske sykehus, noe som kan vœre en indikasjon på at misbrukerne i dette utvalget i større grad også hadde andre psykiatriske diagnoser og av den grunn større selvmordsrisiko. En annen forklaring kan vœre at de to studiene dekker ulike epoker innenfor vårt århundre som er ulike både med hensyn til omfanget av alkoholmisbruk og med hensyn til selvmordsrater.

Både alkoholmisbruk og selvmordsrater var vesentlig lavere, og derved mer marginale fenomener i den første epoken som er dekket av Sundbys studie. Dersom marginalisering og sosial utstøting er av betydning for selvmord blant alkoholmisbrukere, vil selvmordsrisikoen, - og derved også overdødeligheten i selvmord blant alkoholmisbrukere, være større når omfanget av alkoholmisbruk er relativt lite.

Denne typen diskusjon omkring til dels betydelige forskjeller i observerte sammenhenger mellom alkoholmisbruk og selvmord er imidlertid i liten grad beskrevet i forskningslitteraturen.

Det finnes svœrt få oppfølgingsstudier av alkoholmisbrukere som strekker seg over svœrt mange år, og det empiriske grunnlaget har vœrt spinkelt og uklart med hensyn til hvor stor livstidsrisikoen for selvmord er blant alkoholmisbrukere. Noen tidlige studier har anslått at livstidsrisikoen for selvmord blant alkoholmisbrukere lå på 15-20\% (kfr Roy \& Linnoila 1986). Disse studiene er hyppig, og oftest ukritisk, referert i seinere arbeider. Murphy og Wetzel (1991) argumenterte imidlertid for at dette tallet måtte vœre for høyt, og de gjorde et anslag over hvor stor sannsynligheten for selvmord er blant alkoholmisbrukere på grunnlag av en rekke tidligere studier med varierende oppfølgingstid. De kom da til at ca. $5 \%$ av alkoholmisbrukere som har vœrt til behandling ender sitt liv i selvmord. Dette anslaget er imidlertid beheftet med en del usikkerhet.

Men i den norske oppfølgingsstudien som gikk over 40 år etter sesjon (Rossow \& Amundsen 1995), fant vi empirisk holdepunkt for at livstidsrisiko for selvmord blant alkoholmisbrukere ligger i det området som Murphy og Wetzel har anslått, og at omtrent hver 20. mannlige alkoholmisbruker ender sitt liv i selvmord.

Sammenhengen mellom alkoholmisbruk og selvmord har også vœrt studert i retrospektive studier (ofte rettsmedisinske undersøkelser), hvor man har sett på forekomsten av alkoholmisbruk blant dem som har begått selvmord.

Denne typen av studier har også vist store variasjoner i anslagene på omfanget av alkoholmisbruk blant de som er døde ved selvmord, fra i størrelsesorden 10 til $40 \%$ (kfr Retterstøl 1995).

I den norske oppfølgingsstudien av vernepliktige på sesjon, fant vi indikasjoner på et kronisk alkoholmisbruk i hvert 5 . tilfelle av selvmord. Ut fra disse typene av studier på individnivå vet vi imidlertid ikke noe om i hvilken grad alkoholmisbruk er en årsak til selvmord, og i hvilken grad selvmord blant alkoholmisbrukere skyldes seleksjonsmekanismer.

Et gjennomgående trekk ved selvmordsrater i ulike land og kulturer og i ulike perioder er at selvmord forekommer hyppigere blant menn enn blant kvinner. I Norge er selv- 
mordsraten blant menn omtrent 3 ganger så høy som blant kvinner, og i de yngre aldersgruppene (under 25 år) er forekomsten av selvmord nesten 5 ganger høyere blant menn enn blant kvinner (Hytten et al 1995). Kjønnsforskjeller i selvmordsrisiko blant alkoholmisbrukere har vœrt omtalt i noen litteraturoversikter (Roy \& Linnoila 1986; Lester 1992), men det har vœrt gjort $i$ beskjedent omfang og $i$ liten grad på en kritisk vurderende måte. Blant alkoholmisbrukere som har tatt sitt eget liv, har man funnet at det er omtrent 9 ganger så mange menn som kvinner (Roy \&

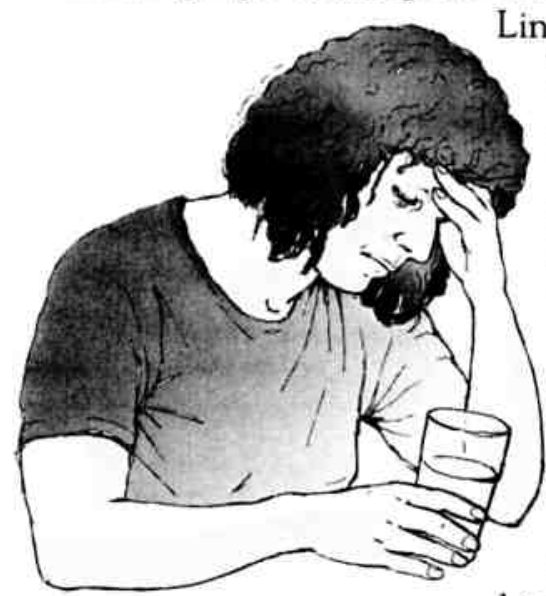

Linnoila 1986), og dette er blitt fortolket som en høyere selvmordsrisiko blant mannlige alkoholmisbrukere sammenliknet med kvinnelige alkoholmisbrukere.

Noen nyere uppfølgingsstudier av alkoholmisbrukere har imidlertid vist at selvmordsrisikoen er omtrent like stor for begge kjønn (Lindberg \& Ågren 1988; Duffy \& Kreitman 1993). Man kan trolig også anta at alkoholmisbruk er like ødeleggende for kvinners sosiale tilhørighet som for menns, og at misbruket derved underminerer en viktig beskyttelsesfaktor for selvmord i like stor grad for de to kjønn. En større overhyppighet av psykiske lidelser blant kvinnelige alkoholmisbrukere sammenliknet med mannlige (Helzer \& Pryzbeck 1988), kunne endog tilsi at selvmordsrisikoen ville vœrt høyere blant kvinner med alkoholmisbruk.

\section{Studier pà makro-nivà}

Selvmord er tilsynelatende et utpreget individualistisk fenomen som henger sammen med egenskaper hos individet. Likevel kan man også, som Durkheim (1951[1897]), se på forekomsten av selvmord $i$ et samfunn som en respons på sosiale fenomener og sosiale endringer på makronivå. Genetiske faktorer og personlighetsegenskaper kan giøre at noen individer er predisponerte for selvmord, mens sosiale eller miljømessige faktorer kan vœre utløsende faktorer for selvmord hos individer som er predisponerte (Norström 1987).

Ved bruk av tidsserieanalyser på aggregert nivå har vi beregnet hvilken effekt en endring i det samlede alkoholkonsumet vil ha på selvmordsrater i Norge. Disse analysene viser at en endring i gjennomsnittlig alkoholkonsum med 1 liter per innbygger per år, er knyttet til en $ø$ kning i selvmordsraten blant menn på ca. 10\% (Rossow 1993). Videre beregninger viser også at omtrent $1 / 3$ av selvmordene blant menn trolig kan tilskrives alkoholkonsum, enten som følge av langvarig misbruk eller som følge av akutt beruselse. Selv om både misbruk og beruselse også har betydning for selvmord blant kvinner, finner vi relativt små effekter på aggregert nivå, rett og slett fordi menn drikker omtrent 3 ganger så mye som kvinner. Dermed blir endringer i gjennomsnittskonsumet i befolkningen i større grad et mål på endringer i misbruk og akutt beruselse blant menn enn blant kvinner.

Gjennom samarbeid $i$ et internasjonalt komparativt prosjekt på alkohol og selvmord (IPAS), har vi også sett på kulturelle variasjoner $i$ betydningen av alkoholkonsum for selvmordsraten. Så langt indikerer disse analysene at i "tørre" alkoholkulturer som Sverige og Norge hvor gjennomsnittlig alkoholkonsum er relativt lavt, gir en endring i konsumet et relativt stort utslag på selvmordsratene for menn, mens i "våte" alkoholkulturer hvor gjennomsnittskonsumet er relativt høyt (f eks i Frankrike og Portugal), gir en tilsvarende endring $i$ alkoholkonsumet et mindre relativt utslag på selvmordstallene. Disse funnene åpner for interessante aspekter med hensyn til den relative betydningen av seleksjonsmekanisme og årsaksmekanismer for sammenhengen mellom alkohol og suicid.

Norström (1995) diskuterer i sin komparative analyse to typer av forklaringer på at endring i alkoholkonsumet gir et mindre relativt utslag på selvmordstallene i en "våt" kultur som Frankrike sammenliknet med en "tørr" kultur som Sverige. For det første vil det vœre større grad av seleksjon til misbruk i en "tørr" kultur og derfor en større grad av "overlapping" mellom alkoholmisbruk og predisponerende faktorer for selvmord, noe som igjen gir en sterkere sammenheng mellom alkohol og selvmord. For det andre er alkolmisbruk eller et svœrt høyt alkoholkonsum i større grad et marginalisert fenomen i en "tørr" kultur, og risikoen for selvmord kan derfor vœre høyere som følge av de sosiale reaksjonene på alkoholbruken.

For videre forskning vil det vœre viktig å empirisk etterprøve om drikkekulturenes betydning utelukkende er knyttet til totalkonsumet, eller om drikkem ønstre (f eks omfang av beruselse) også har betydning for kulturelle variasjoner i sammenhenger mellom alkohol og selvmord på makronivå.

Forskning omkring alkohol og selvmord har frambragt mye og relativt entydig kunnskap om sammenhenger mellom alkoholkonsum og selvmord. Likevel gjenstår det forskningsmessig uløste oppgaver og politiske utfordringer på dette området. Blant annet vil det vœre viktig å forstå mer av mekanismene som genererer de observerte sammenhengene, deres relative betydning og hvordan vi kan frambringe forskningsbasert kunnskap som har betydning for primœrforebyggende tiltak og for politiske beslutninger, blant annet med hensyn til rusmiddelpolitikk.

Fortsetter side 23 (litteratur) 
fortsatt fra side 17

Personer med affektiv lidelse har overdødelighet av suicid og av hjertekarsykdommer. En unders $\varnothing$ kelse av Ahrens og medarbeidere, viser at under litiumbehandling reduseres den sterke overdødeligheten til et nivå nær dødeligheten i befolkningen generelt (11). Fortsatt så man høyere forekomst av suicid i den litiumbehandlede pasientgruppen sammenlignet med befolkningen generelt, men reduksjonen i selvmordsfrekvensen under litiumbehandling var uttalt.

En fersk unders $\varnothing$ kelse som ved bruk av avansert statistikk gjør en kritisk gjennomgang av tidligere studier, finner at dødeligheten hos litiumbehandlede pasienter ikke er signifikant forskjellig fra normalbefolkningen (12).

Isometsä og medarbeidere unders $\varnothing$ kte omstendighetene rundt 1397 suicid i Finland (13). Av disse hadde 20 brukt litium som profylakse og behandling av affektiv lidelse de siste 3 måneder av livet. Kun 8 av disse 20 hadde adekvat litiumprofylakse da de suiciderte.

De fleste andre studier har hatt som siktemål å vise nytten av litium til å forebygge suicid. Denne så derimot på tilfeller hvor behandlingen har sviktet, for derved å kunne identifisere faktorer som begrenser nytten av litium som selvmordsforebyggende behandling. Artikkelen konkluderer med at ikkecompliance, det vil si at pasienten ikke tar medikamentet som forskrevet, var den viktigste faktor som begrenset nytten av litium som selvmordsforebyggende medikament.

\section{Konklusjon:}

Litium er viktigste medikament til å forebygge nye sykdomsepisoder ved bipolar sykdom og kan også fors $\varnothing$ kes ved andre affektive lidelser. I tillegg til å bidra til å hindre nye sykdomsepisoder hos de fleste, er det mulig at litium også kan ha en spesifikk effekt til å begrense selvmordsatferd, særlig ved lengre tids behandling. Basert på kunnskap fra senere års studier, anbefales at leger overveier fortsatt litiumbehandling også hos tilsynelatende ikkerespondere, spesielt der pasienten tidligere har vist suicidal atferd.

\section{Litteratur:}

1. Goodwin FK, Jamison KR. Manic-depressive illness. Oxford University Press, New York 1990

2. American Psychiatric Association: Practice guideline for the Treatment of Patients With Bipolar Disorder. Am J Psychiatr 1994; 151: 12 (suppl)

3. Lundquist G. Prognosis and course of manicdepressive psychoses: a follow-up study of 319 first admissions. Acta Psychiatr Neurol 1945: suppl 35: $1-96$
4. Barraclough B. Suicide prevention, recurrent affective disorder and lithium. Br J Psychiatry 1972 121: 391-392

5. Poole AJ, James HD, Hughes WC. Treatment experiences in the lithium clinic at St.Thomas Hospital. J R Soc Med 1978; 71: 890-894

6. Hanus H, Zapletalek M. Sebevrazedna aktivita nemocnych afektivnimi poruchami v prubehu lithioprofylaxe. Ceskoslovenska Psychiatrie 1984; 80: $97-100$

7. Causemann B, Müller-Oerlinghausen B. Does lithium prevent suicides and suicide attempts? In: Birch Nj ed: Lithium: Inorganic Pharmacology and Psychiatric Use. Oxford: IRL Press, 1988. pp 23-24

8. Coppen A, Standish-Barry H, Bailey J, Houston $G$, Silcocks P, Hermon C. Does lithium reduce the mortality of recurrent mood disorders?

J Affect Disord 1991; 23: 1-7

9. Müller-Oerlinghausen B, Müser-Causemann B, Volk J. Suicides and parasuicides in a high-risk patient group on and off lithium long-term medication. J Affect Disord 1992; 25: 261-270

10. Müller-Oerlinghausen B, Wolf T, Ahrens B, Schou M, Grof E, Grof P, Lenz G, Simhandl C, Thau K, Wolf R. Mortality during initial and during later lithium treatment. A collaborative study by the International Group for the Study of Lithiumtreated Patients. Acta Psychiatr Scand 1994; 90: 295-297

11. Ahrens B, Müller-Oerlinghausen B, Schou M, Wolf T, Alda M, Grof E, Lenz G, Simhandl C, Thau K, Vestergaard P, Wolf R, Möller HJ. Excess cardiovascular and suicide mortality of affective disorders may be reduced by lithium prophylaxis. J Affect Disord 1995; 33: 67-75

12. Wolf T, Müller-Oerlinghausen B, Ahrens B, Grof P, Schou M, Felber W, Grof E, Lenz G, Nilsson A, Simhandl C, Thau K, Vestergaard P, Wolf R. How to interpret findings on mortality of long-term lithium treated manic-depressive patients? Critique of different methodological approaches J Affect Disord 1996; 39: 127-132

13. Isometsä E, Henriksson M, Lönnquist J.

Completed suicide and recent lithium treatment. J Affect Disord 1992; 26: 101-104

fortsatt fra side 14

\section{Litteratur}

Duffy, J. \& Kreitman, N. (1993): Risk factors for suicide and undetermined death among in-patient alcoholics in Scotland. Addiction, 88: 757-766.

Durkheim, E. (1951[1897]) Suicide: a study in sociology. New York: Free Press.

Helzer, J.E. \& Pryzbeck, T.R. (1988): The co-occurrence of alcoholism with other psychiatric disorders in the general population and its impact on treatment. Journal of Studies on Alcohol, 49: 219-224.

Hytten, K., Mehlum, L. \& Gjertsen, F. (1995): Rom for unge liv. Selvmord hos barn og ungdom. Utviklingen i Norge de siste 20 år. Forklaringsfors $\phi \mathrm{k}$. Oslo: Universitetet i Oslo.

Lester, D. (1992): “Alcoholism and drug abuse". In Maris, R.W., Berman, A.L., Maltsberger, J.T. \& Yufit, R.I. (Eds) Assessment and prediction of suicide. New York: The Guilford Press.

Lindberg, S. \& Ågren, G. (1988): Mortality among male and female hospitalized alcoholics in Stockholm 1962-1983. Addiction, 83: 1193-1200.

Murphy, G.E. \& Wetzel, R.D. (1990): “The lifetime risk of suicide in alcoholism". Archives of Genera Psychiatry, 47: 383-392.
Nicholls, P., Edwards, G. \& Kyle, E (1974): "Alcoholics admitted to four hospitals in England. II General and cause- specific mortality". Quarterly Journal of Studies on Alcohol, 35: 841-855.

Norström, T. (1987): A time series analysis of the Swedish suicide rate 1915 - 1968. In: Bergryd, U \& Janson, C.-G. Sociological Miscellany, Essays in honour of Gunnar Boalt. Stockholm: University of Stockholm.

Norström, T. (1995): "Alcohol and suicide: comparative analysis of France and Sweden". Addiction, 90: 1463-1469.

Retterst $\varnothing 1$, N. (1995): Selumord. Oslo: Universitetsforlaget.

Rossow, I. (1993): "Suicide, alcohol and divorce; aspects of gender and family integration". Addiction, 88: 1659-1665.

Rossow, I. \& Amundsen, A. (1995): “Alcohol abuse and suicide: a 40-year prospective study of Norwegian conscripts”. Addiction, 90: 685-691.

Roy, A. \& Linnoila, M. (1986): “Alcoholism and suicide". Suicide and Life-Threatening Behavior, 16: 162-191.

Skog, O.-J.(1991): Alcohol and suicide - Durkheim revisited. Acta Sociologica, 34: 193-206.
Sundby, P. (1967): Alcoholism and mortality. Oslo: Universitetsforlaget.

Vaillant, G. E. (1983): The natural history of alcoholism. Cambridge MA: Harvard University Press.

\section{STILLING LEDIG}

Seksjon for selvmordsforskning og -forebygging har ledig heltidsstilling for overlege (spes. psykiatri eller annen relevant spesialitet) eller psykologi I med tiltredelse snarest. Interesserte bes studere fullstendig utlysningstekst i Tidsskrift for Den norske lægeforening eller i Tidsskrift for Den norske psykologforening, eller kontakte overlege Lars Mehlum, tlf. 22923473. 